\title{
FTIR and FT-PL Spectroscopic Analysis of TPV Materials and Devices
}

J.D. Webb, L.M. Gedvilas, M.R. Olson,

X. Wu, A. Duda, M.W. Wanlass, and K.M. Jones

National Renewable Energy Laboratory

Presented at the $4^{\text {th }}$ Conference on

Thermophotovoltaic Generation of Electricity

Denver, Colorado

October 11-14, 1998

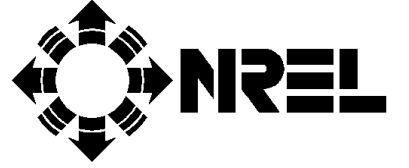

National Renewable Energy Laboratory 1617 Cole Boulevard Golden, Colorado 80401-3393

A national laboratory of the U.S. Department of Energy Managed by Midwest Research Institute for the U.S. Department of Energy under contract No. DE-AC36-83CH10093

Work performed under task number WU6H0205

October 1998 


\begin{abstract}
NOTICE
This report was prepared as an account of work sponsored by an agency of the United States government. Neither the United States government nor any agency thereof, nor any of their employees, makes any warranty, express or implied, or assumes any legal liability or responsibility for the accuracy, completeness, or usefulness of any information, apparatus, product, or process disclosed, or represents that its use would not infringe privately owned rights. Reference herein to any specific commercial product, process, or service by trade name, trademark, manufacturer, or otherwise does not necessarily constitute or imply its endorsement, recommendation, or favoring by the United States government or any agency thereof. The views and opinions of authors expressed herein do not necessarily state or reflect those of the United States government or any agency thereof.
\end{abstract}

Available to DOE and DOE contractors from:

Office of Scientific and Technical Information (OSTI)

P.O. Box 62

Oak Ridge, TN 37831

Prices available by calling 423-576-8401

Available to the public from:

National Technical Information Service (NTIS)

U.S. Department of Commerce

5285 Port Royal Road

Springfield, VA 22161

703-605-6000 or 800-553-6847

or

DOE Information Bridge

http://www.doe.gov/bridge/home.html 


\title{
FTIR and FT-PL Spectroscopic Analysis of TPV Materials and Devices
}

\author{
J. D. Webb, L. M. Gedvilas, M. R. Olson, X. Wu, A. Duda, \\ M. W. Wanlass, K. M. Jones \\ National Renewable Energy Laboratory, 1617 Cole Blvd., Golden, CO 80401
}

\begin{abstract}
Fourier transform (FT) spectroscopic techniques are useful in determining properties of thermophotovoltaic (TPV) materials and devices. The III-V TPV absorber materials have energy bandgaps that can be optimized for conversion of the near-infrared radiation emitted by thermal sources in the $1000^{\circ}-1200^{\circ} \mathrm{C}$ temperature range. The bandgaps of these materials can be measured at room temperature using FT-photoluminescence spectroscopy, which can be done with a modified FT-Raman spectrophotometer operating in the near-infrared spectral region. The intensities and bandwidths of the FT-PL spectra also provide information on the extent of non-radiative recombination and the compositional uniformity of the materials. To achieve adequate operating efficiencies, TPV converters must return sub-bandgap radiation to the thermal source. The percent reflectance of the device in the mid-infrared spectral region is therefore an important operating parameter that can be accurately measured using FT-infrared (FTIR) spectroscopy with total reflectance optical accessories. In this paper, we discuss applications of these techniques to TPV materials and devices, and variations on these approaches, such as scanning micro-FT-PL spectroscopy, that enable microanalysis of TPV device structures at the $1-100-\mu \mathrm{m}$ scale.
\end{abstract}

\section{INTRODUCTION}

Infrared reflectance and transmittance are important properties of thermophotovoltaic (TPV) devices. In order to convert infrared radiation supplied by conventional energy sources, i.e., fossil fuel, to electricity with high efficiencies, TPV devices must absorb band-gap radiation while reflecting most of the sub-bandgap radiation back to the thermal radiative source (1). Fourier transform infrared (FTIR) spectroscopy is the dominant technique for measuring the infrared spectra of materials at wavelengths ranging from 1.3 to $25 \mu \mathrm{m}$ (2). The use of FTIR specular reflectance spectroscopy to assess the performance of TPV front surface (3) and back surface (4) reflectors is well-established.

Photoluminescence (PL) spectroscopy is used extensively to measure properties of semiconductor thin films used in photovoltaic (PV), electronic, and optoelectronic devices. For example, near-infrared (NIR) PL spectroscopy has been used to detect light- or heat- induced defects ("dangling bonds") in hydrogenated amorphous silicon (5) and has been correlated with the efficiency of PV devices produced from copper indium diselenide ( $\mathrm{CuInSe}_{2}$, or CIS) thin films (6). Although some of this work has been done at room temperature, detection of weak NIR PL emission beyond the wavelength range of $\mathrm{Si}$ and photomultiplier detectors when using dispersive 
spectrophotometers has typically required cryogenic cooling of semiconductor samples $(5,6)$.

FTIR spectroscopy offers substantial improvements in the analysis of weak signals over dispersive infrared spectroscopy through Jacquinot's throughput advantage (2). A variety of PL measurements, with FTIR detection that exploits this advantage, have been reported on NIR PL emitters. Recent work has involved the use of FT-Raman spectrophotometers, rather than laser-excitation sources, coupled with FTIR spectrophotometers, to obtain room-temperature and cryogenic PL and electroluminescence spectra from a variety of bulk and thin-film semiconductor materials having PV applications (7-10). Use of an FT-Raman spectrophotometer for FT-luminescence measurements is advantageous because the luminescence processes occur with quantum efficiencies many orders of magnitude higher than that for the Raman scattering process, which for NIR excitation is of the order of $10^{-6}(11)$. Thus, the FT-Raman instrumentation is highly sensitive to NIR PL even at room temperature; in fact, excitation power must be reduced to sub-milliwatt levels in some cases to avoid band-filling artifacts and localized sample heating (10).

Silicon, germanium, and the III-V and II-VI compound semiconductors all emit luminescence bands within the range of the FT-Raman instrumentation, with some modifications that will be discussed. We have used FT-PL spectroscopy with other analytical techniques to solve problems such as junction formation and surface passivation in CIS PV devices (10), determination of optical gap and strain-induced effects on recombination rates in III-V TPV materials and devices (12), and band-gap analysis of graded-composition TPV devices (13). In the present work, we will focus on the results of FTIR reflectance and FT-PL analyses of TPV materials and devices.

\section{EXPERIMENTAL APPROACH}

Cadmium stannate films were grown as described previously (3). TPV device structures and undoped device analog structures (12) incorporating $\mathrm{Ga}_{\mathrm{x}} \mathrm{In}_{1-\mathrm{x}} \mathrm{As}$ or InAs $\mathrm{P}_{1-\mathrm{y}}$ absorber and graded composition (graded $\mathrm{x}$ ) layers were grown using metalorganic vapor-phase epitaxy (MOVPE) on InP substrates (1). The detailed structure of the multilayer $\mathrm{Ga}_{\mathrm{x}} \mathrm{In}_{1-\mathrm{x}}$ As samples is shown in the figures accompanying the results and discussion. Continuously graded layers (CGL) and step-graded layers (GL) are used in lattice-mismatched (LMM) devices and analog structures to enable epitaxial growth while controlling bandgap by varying $x$ or $y$, respectively, in the $\mathrm{Ga}_{x} \mathrm{In}_{1-\mathrm{x}} \mathrm{As}$ or InAs $\mathrm{P}_{1-y}$ films (1).

We used a SpectraTech FT-30 specular reflectance (SR) accessory operated at a fixed-incidence angle of $30^{\circ}$ from the sample normal to obtain large-area SR spectra of the TPV samples. SR measurements were also made using a Spectra-Tech Model 500 variable-angle accessory with incidence-angle variable between $20^{\circ}$ and $80^{\circ}$. We used a Labsphere Model RSA-NI-550D integrating sphere with fixed-incidence angle of $10^{\mathrm{O}}$ and integral deuterated triglycins sulfate (DTGS) detector to obtain large-area total reflectance (TR) data on the TPV samples. The latter instrument was fitted with 
a $1 / 2$ "-diameter circular aluminum aperture at the $3 / 4$ "-diameter sample port to allow analysis of smaller-sized samples, plus a light trap placed below the samples to eliminate spurious reflection from the sample mount. Attempts to incorporate smaller apertures reduced the accuracy of the TR measurements. All of these attachments could be fitted with a Perkin-Elmer $\mathrm{AgBr}$ wire-grid IR polarizer. We also submitted some samples to Surface Optics Corporation (San Diego, CA 92131) for TR analysis using their SOC-100 hemispherical reflectometer accessory, which has an integral DTGS detector and incidence-angle variable between $10^{\mathrm{O}}$ and $80^{\mathrm{O}}$. All of these accessories were used in conjunction with a Nicolet Magna 550 FTIR spectrophotometer with DTGS detector operated at $16 \mathrm{~cm}^{-1}$ resolution.

A novel FT-PL system, based on the Nicolet 960 dedicated FT-Raman spectrophotometer (operated at $8 \mathrm{~cm}^{-1}$ resolution), was used for the measurements on TPV devices and materials. The instrument includes a diode-pumped, Nd: $\mathrm{YVO}_{4}$ excitation laser operating at $1064 \mathrm{~nm}$, an $\mathrm{LN}_{2}$-cooled, Zn-doped Ge detector, $180^{\circ}$ reflective sampling optics in the main sample compartment, and a scanning, autofocusing Raman microscope with $1-\mu \mathrm{m}$ positioning precision and video capture for visible light microphotography of the samples analyzed. A Spectra-Tech 32x Reflachromat reflective objective and an Olympus 100x MS Plan 100 objective enabled microscope-excitation spot diameters of $10.0 \mu \mathrm{m}$ and $1.2 \mu \mathrm{m}$, respectively.

Several features were added to the 960 instrument to extend its capabilities for FT-PL spectroscopy. Its long-wavelength range was extended from $1750 \mathrm{~nm}$ (the Ge detector limit) to $2700 \mathrm{~nm}$ by adding a. cold-filtered InSb detector (Graseby Infrared). A Melles-Griot Model 06 DLL 807 GaAs diode laser operated at $847 \mathrm{~nm}$ by a MellesGriot Model 06 DLD 103 controller was installed in the interlocked instrument housing with an optical isolator. The laser delivers $30 \mathrm{~mW}$ of excitation power to the main sampling compartment. Together with a Kaiser 850-nm holographic notch filter in the emission-beam path, the GaAs laser extended the short-wavelength range of the spectrophotometer from $1075 \mathrm{~nm}$ to $870 \mathrm{~nm}$ for PL measurements. Mounts for neutral density filters in the main sampling compartment and microscope excitationbeam paths enabled low-excitation power levels, which are especially important to avoid band-filling and sample overheating effects in FT-PL micro-spectroscopy. The FT-PL data were taken at $300 \mathrm{~K}$, although sample cooling to $30 \mathrm{~K}$ is possible $(10,13)$.

\section{RESULTS AND DISCUSSION}

\section{FTIR Reflectance Measurements}

The influence of sub-bandgap reflectance on the efficiency of TPV systems has been described $(1,14)$. The strong correlation between these variables means that even variations of a few percent in the return of sub-bandgap (mid-IR) photons to the thermal radiator will have a profound influence on TPV system performance. For this reason, accurate measurements of TPV device or device filter reflectance are needed. To assess accuracy, we compared the mid-IR reflectance data measured for a series of 
cadmium stannate plasma filters using unpolarized $\mathrm{SR}\left(30^{\mathrm{O}}\right.$ incidence) with unpolarized TR data taken using the integrating sphere $\left(10^{\mathrm{O}}\right.$ incidence) and the absolute reflectometer $\left(30^{\mathrm{O}}\right.$ incidence). We found that for rough samples (diffuse reflectors), the two TR measurements were comparable (Fig. 1), while the SR measurement gave lower values, as expected to result from Rayleigh scattering. For smooth samples, reflectance was higher for the accessories having a higher incidence angle, also as expected. The agreement between the results obtained using the two different TR accessories is encouraging. The SR measurements are within three percent of the TR measurements, a numerically small but significant difference.

Reflectance measurements on TPV devices are more challenging because of their fragility, complexity, and small size. In Fig. 2 we present the effects on the TR spectrum of successive application of a magnesium fluoride/titanium/gold backsurface reflector (BSR) and a magnesium fluoride/zinc selenide anti-reflective (AR) coating onto a TPV device with $\mathrm{SiO}_{2}$ backing. The spectra were measured using the FTIR integrating sphere. The effect of the BSR, which appeared highly specular, in increasing device reflectance is very evident. However, application of the AR coating had little or no effect on the sub-bandgap reflectance of the device. The reflectance minima at 10 and 15 microns in Fig. 2 correspond to lattice absorption by the InP substrate and absorption by $\mathrm{Fe}$ centers in the InP substrate, respectively.

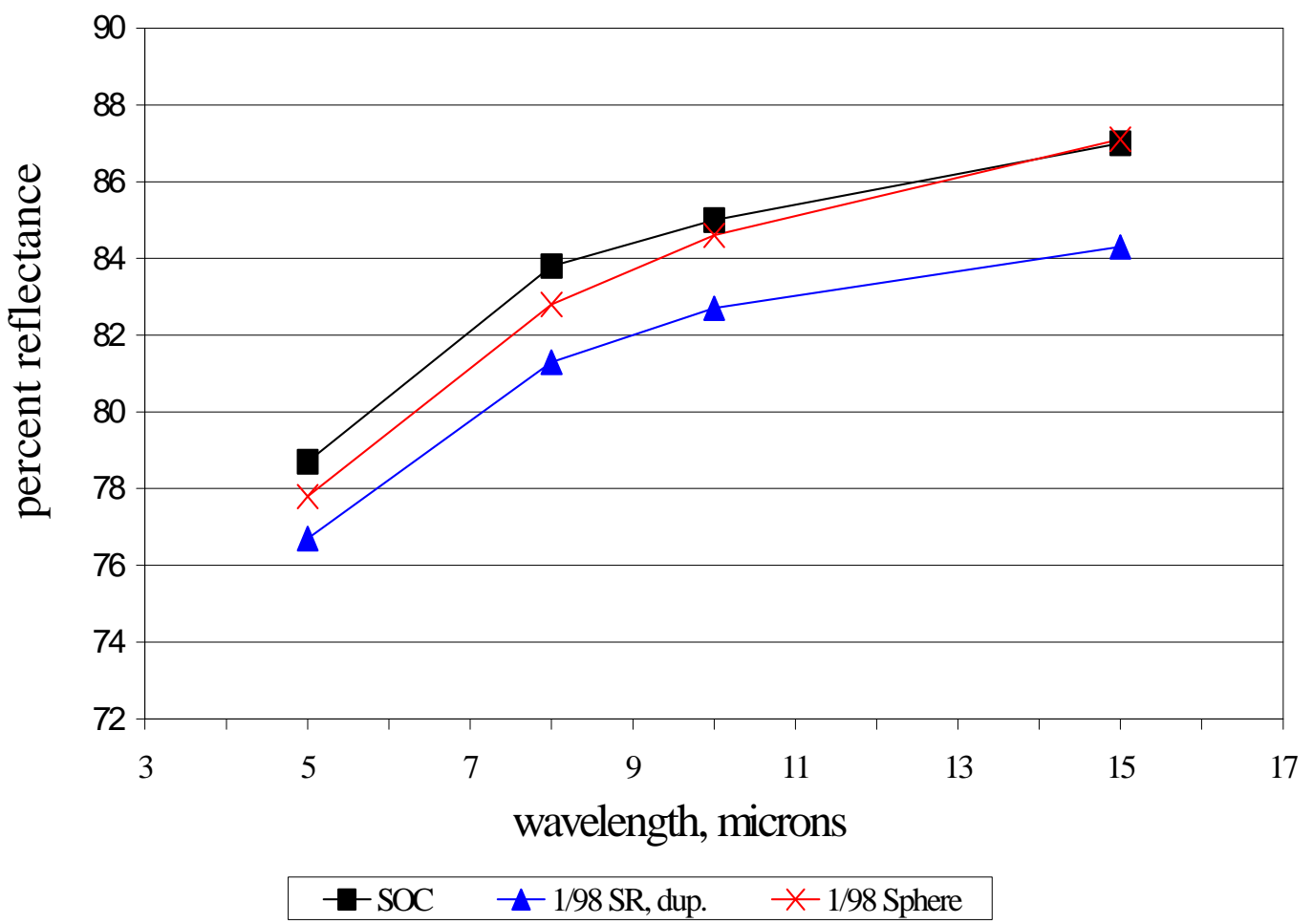

FIGURE 1. FTIR reflectance measurements of a diffuse CdSnO4/glass film. 


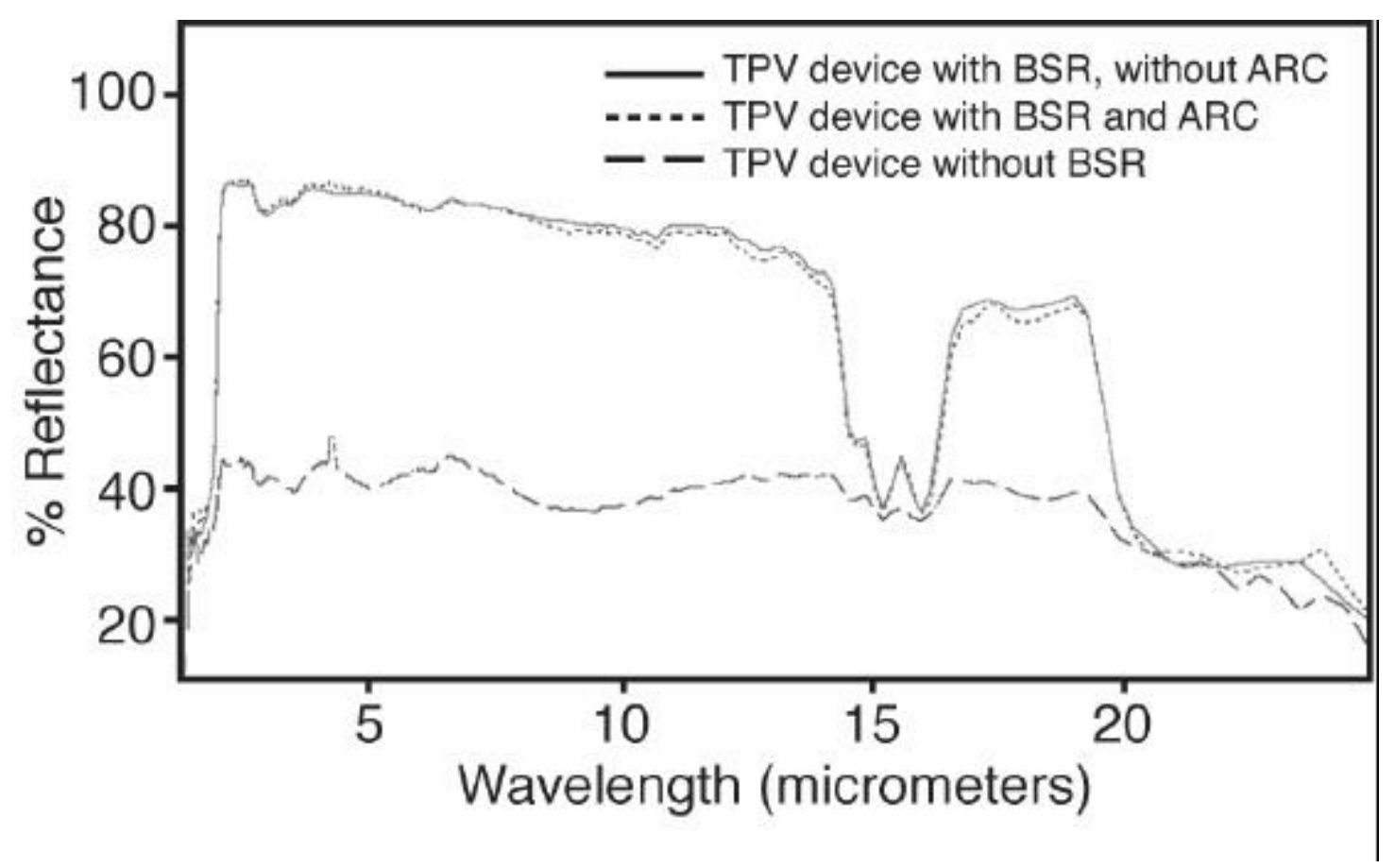

FIGURE 2. Effect of back-surface reflector and antireflective coating on total reflectance of TPV Device 1-236b.

We verified the effect of orientation of the gridlines on monolithic interconnected minimodule (MIM) TPV device structures with respect to the plane of incidence of IR radiation in the integrating sphere reported by Ballinger (15). At $2.5 \mu \mathrm{m}$, the TR of a typical MIM structure without a BSR is about $2 \%$ lower with the device trenching and gridlines perpendicular to the incidence plane in the integrating sphere, and 5\% lower for the same device with a gold BSR, regardless of polarization of the incident beam. By performing polarized transmittance measurements on the MIM structure without a BSR, we found that the device transmittance is sensitive to polarization. The device acts similarly to a wire-grid polarizer in that it polarizes light in the direction perpendicular to the conductive grid pattern. The device-polarization ratio (Fig. 3) exhibits a minimum near $4 \mu \mathrm{m}$ and a continuing decrease at longer wavelengths corresponding with orientation of the device gridlines parallel to the direction of polarization, with some fine structure corresponding to lattice absorption bands. The long-wavelength decrease correlates with the grid spacing $(100 \mu \mathrm{m}$ between trenches and top contacts). However, the light-trapping effect dominates the polarization effect in the reflectance measurements. We made variable-angle SR measurements (not shown) of MIM TPV Device 1-223b with a mechanically contacted gold BSR, which showed that the device reflectance decreased strongly with increasing incidence angle from $20^{\circ}$ to $45^{\circ}$ when the device gridlines were perpendicular to the incidence plane. The SR measurements may overestimate this decrease because of Rayleigh scattering 
from the device structures, however, no such decrease in SR was noted when incidence angle was increased with the device gridlines oriented in the plane of incidence. More accurate measurements of the angle-dependent TR of the MIM structures could be made using the SOC-100 variable-angle hemispherical reflectometer, but the light-trapping character of the device structure for non-normal incident radiation is evident from our current results.

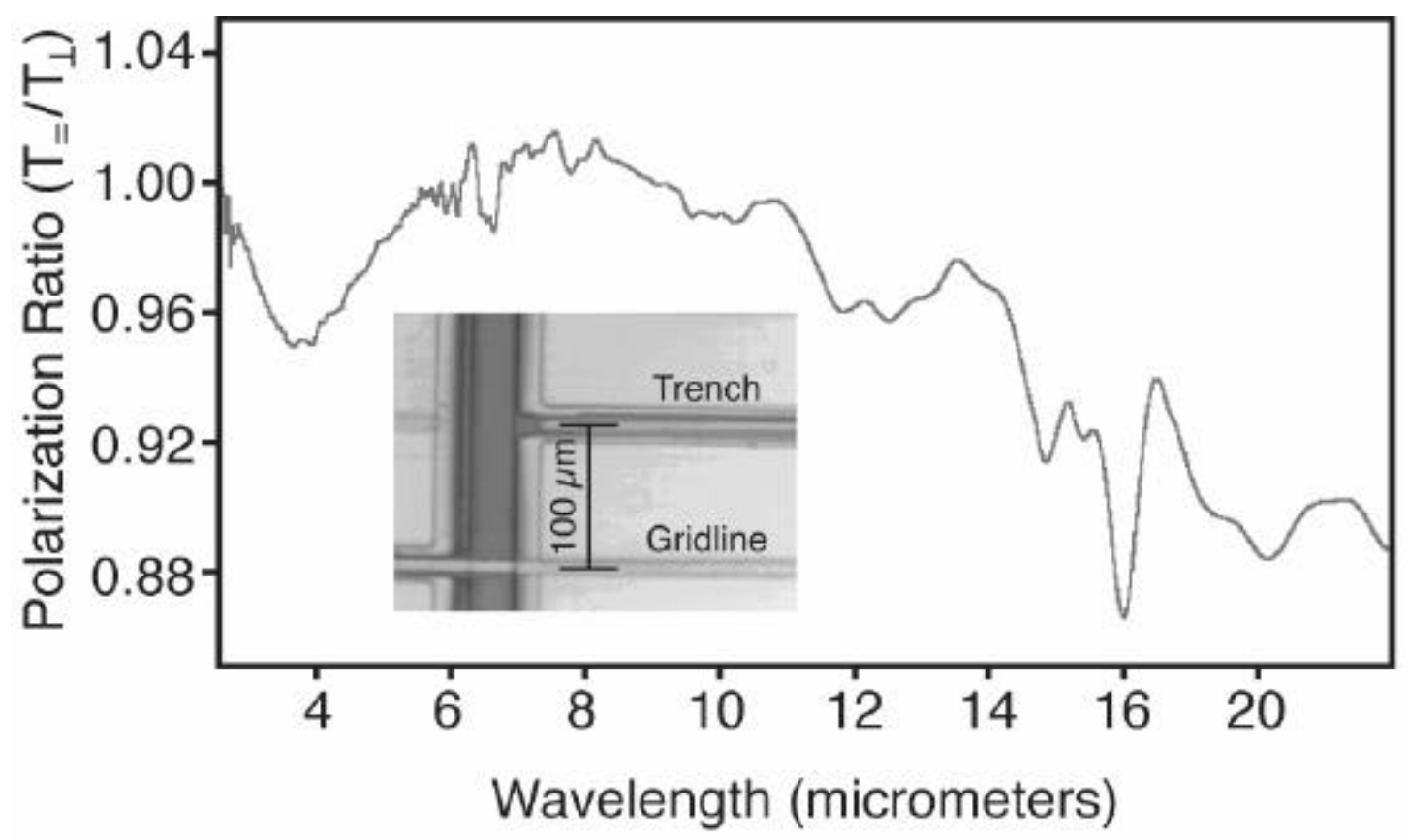

FIGURE 3. Polarization ratio for MIM device structure \#1-223b (no BSR), ratio of $\mathrm{T}$ with [gridlines parallel]/[gridlines perpendicular] to direction of polarization.

\section{FT-Photoluminescence Measurements}

Figure 4 shows the relationship between the TR and the FT-PL spectra of a $\mathrm{Ga}_{0.47} \mathrm{In}_{0.53} \mathrm{As}$ MIM TPV device with a gold BSR. The correspondence between the low-energy TR and PL band edges is close for this device, which was lattice-matched (LM) to InP and did not incorporate a graded layer (GL). The PL maximum is higher in energy than the reflectance band edge by less than kT, and it may be possible to use TR spectra collected from non-graded BSR films and devices to validate an algorithm for calculating the bandgap from FT-PL spectra.

In (12) we showed that the intensity of PL collected from undoped, latticemismatched (LMM) $\mathrm{Ga}_{\mathrm{x}} \mathrm{In}_{1-\mathrm{x}}$ As samples is more than an order of magnitude lower than that collected from a LM sample. The compositional red shift of the PL band maxima as $\mathrm{x}$ is decreased from the InP-LM value of 0.47 is within $\mathrm{kT}$ of the predicted bandgap for this material $(1,12,16)$. 
Total Reflectance of Monolithic Minimodule 1-153

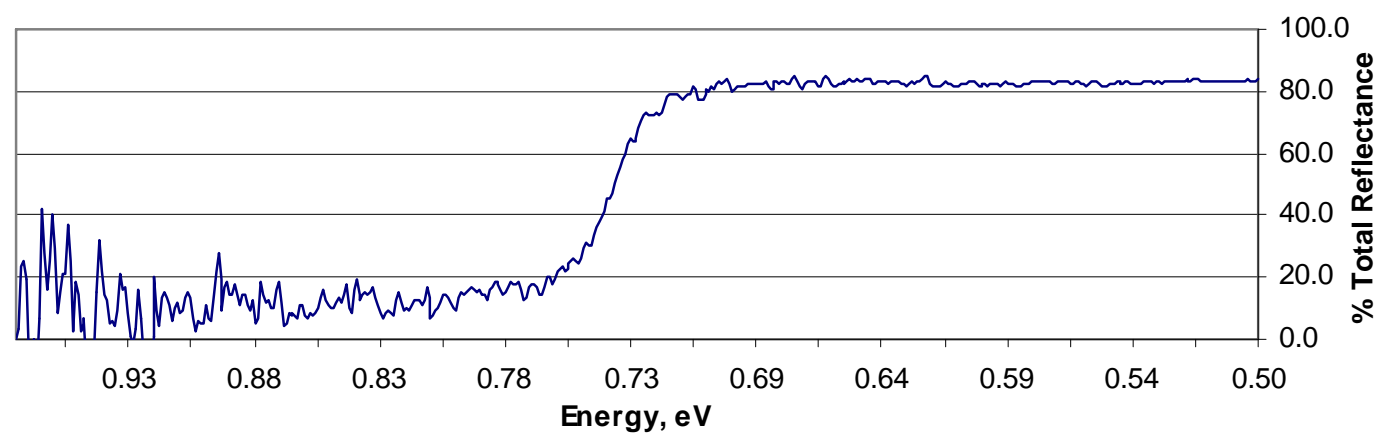

FT-PL of Monolithic Minimodule 1-153

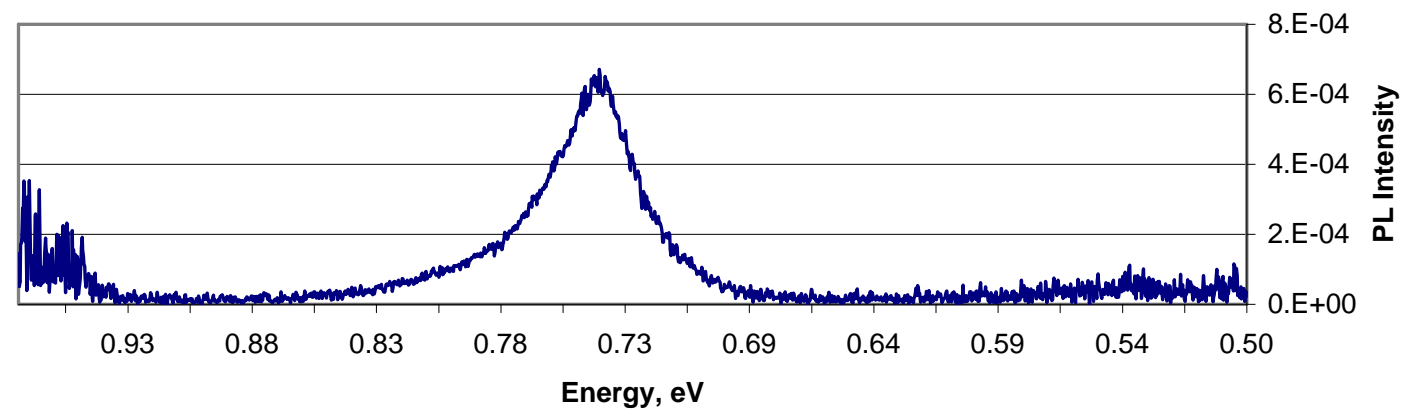

FIGURE 4. Total reflectance and FT-photoluminescence spectra of TPV device \#1-153 .

In (13) the results of high spatial resolution $(\sim 1 \mu \mathrm{m})$ FT-PL spectroscopy of TPV device 1-213 were given. The spectra were taken on the cleaved edge of the device, with one spectrum collected in the $\mathrm{Ga}_{\mathrm{x}} \mathrm{In}_{1-\mathrm{x}} \mathrm{As} \mathrm{p} / \mathrm{n}$ absorber layer $(\mathrm{x}=0.32)$, and another in the GL, close to the absorber layer. The device structure is given in Fig. 5. The technique has sufficient resolution to distinguish the two thicker $\operatorname{Ga}_{\mathrm{x}} \mathrm{In}_{1-\mathrm{x}} \mathrm{As}$ layers. A lower PL intensity, implying a relative increase in the rate of non-radiative recombination because of $\mathrm{LMM}$ in the GL, is evident in the spectrum of the absorber layer relative to that of the GL.

Fig. 5 shows the locations of an 18-step line map superimposed on a micrograph of angle-lapped TPV device 1-213. Angle-lapping was done at an angle of $2.5^{\mathrm{O}}$ or less to the device plane using a chemical/mechanical polishing medium consisting of $0.05 \mu \mathrm{m}$ non-crystallizing colloidal silica in basic solution. This procedure exposed lapped surfaces of 180 to 400 microns, enabling use of the 32x microscope objective $(10 \mu \mathrm{m}$ excitation spot diameter) to resolve device layers as thin as $\left[10 \mu \mathrm{m} * \sin \left(2.5^{\circ}\right)\right]=0.4$ $\mu \mathrm{m}$ or less. The scan began on the contact cap layer surface, and progressed through the lapped absorber and GL to the InP substrate. A thin vertical line is visible just to the left of the center of the lapped device surface, which corresponds to the position of the lower confinement layer (1) in this device. Note that the "device layer" scale on Figure 5 and in subsequent figures is approximate in that it assumes planarity of the 
angle-lapped surface and is given only for reference. The scale ignores the thinner device layers, which were not detectable by FT-PL microspectroscopy. The PL intensity decreases as the lapped region is traversed during the linear scan.

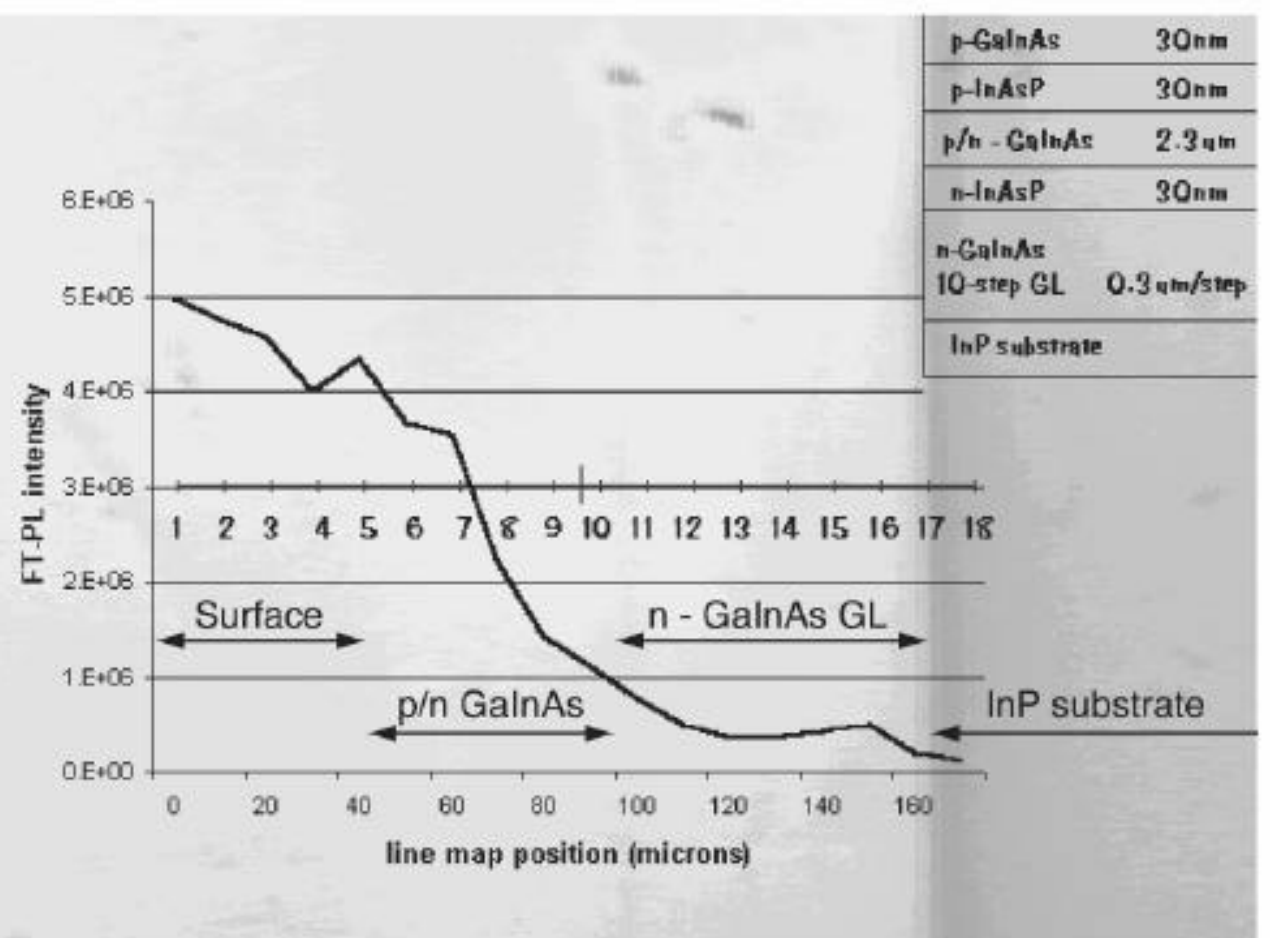

FIGURE 5. FT-PL peak intensity (InSb detector) vs. line map position for TPV device \#1-213, superimposed on a micrograph of the device. The number line shows where the FT-PL spectra were collected on the angle-lapped device.

Figure 6 is a three-dimensional plot of the corrected FT-PL spectra obtained from the line map of the angle-lapped device, versus scan position in microns. A strong, sharp PL spectrum was obtained from the device surface, apparently from the absorber layer through the thin cap and upper confinement layers. The PL intensity dropped to some extent as the absorber layer was traversed during the scan, but stayed relatively high until the GL was approached. PL intensity dropped rapidly as the GL was traversed, implying a relative increase in the rate of non-radiative recombination due to LMM, and the energy and bandwidth of the PL spectrum both increased. No PL was collected from the final scan point, in the InP substrate. During this scan, only PL emission characteristic of $\mathrm{Ga}_{\mathrm{x}} \mathrm{In}_{1-\mathrm{x}} \mathrm{As}$, i.e., having energies between 0.74 and $0.60 \mathrm{eV}$, was observed. Even with angle-lapping, the 32x objective has insufficient spatial resolution to collect PL from the cap and confinement layers, and the confinement layer and substrate bandgaps ( $1 \mathrm{eV}$ and $1.34 \mathrm{eV}$, respectively) are beyond the upper limit of the InSb detector response range. The detector cannot be switched to $\mathrm{Ge}$ during a scan with the current scanning software, and a higher-energy laser source 
would be required to excite PL from the substrate. Attempts to resolve PL from the confinement layers in the angle-lapped device using the 100x objective with 1064-nm excitation and Ge detector were not successful. Apparently the limited optical throughput of the 100x objective, the shallow absorption depth of the confinement layer, or damage to the confinement layer during lapping reduced the PL signal below detection limits.

The energies of the corrected PL band maxima are plotted as a function of scan position, with the predicted $\mathrm{E}_{\mathrm{g}}(\mathrm{x})$ of the $\mathrm{Ga}_{\mathrm{x}} \mathrm{In}_{1-\mathrm{x}} \mathrm{As}$ device structure, in Fig. 7 . The agreement between the PL peak energies and the predicted direct bandgap of $\mathrm{Ga}_{\mathrm{x}} \mathrm{In}_{1-\mathrm{x}}$ As at $300 \mathrm{~K}(16)$,

$$
E_{g}(x)=\left(0.555 x^{2}+0.505 x+0.356\right)
$$

is within $\mathrm{kT}(0.026 \mathrm{eV})$, with the maxima of the PL peaks at energies above the predicted bandgap. The value of $\mathrm{x}$ is constant at 0.32 in the absorber layer, and varies from 0.32 to 0.47 (InP-LM) in the GL. The difference between the PL maxima and

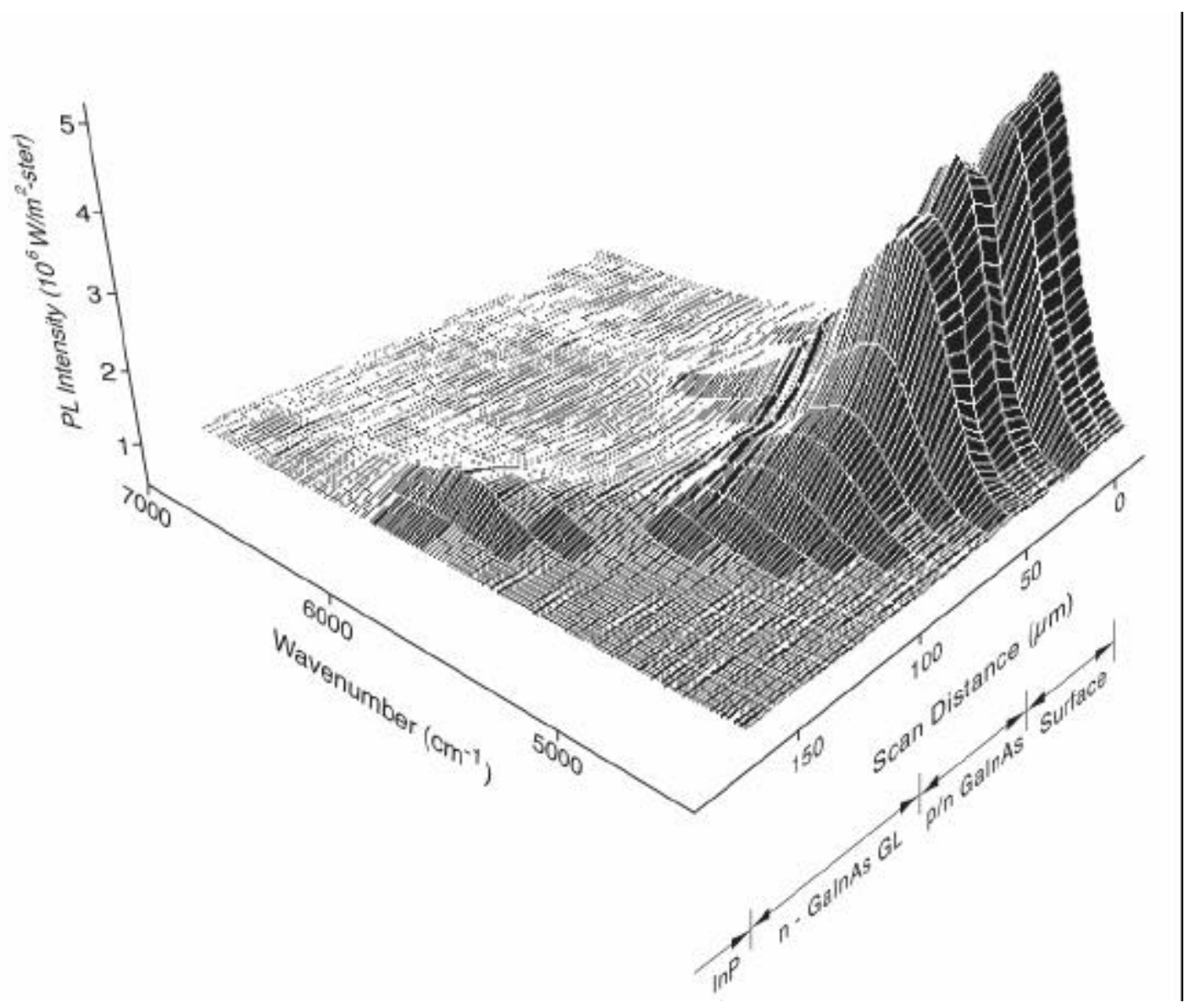

FIGURE 6. FT-PL spectra vs. line map position on angle-lapped TPV device \#1-213. 


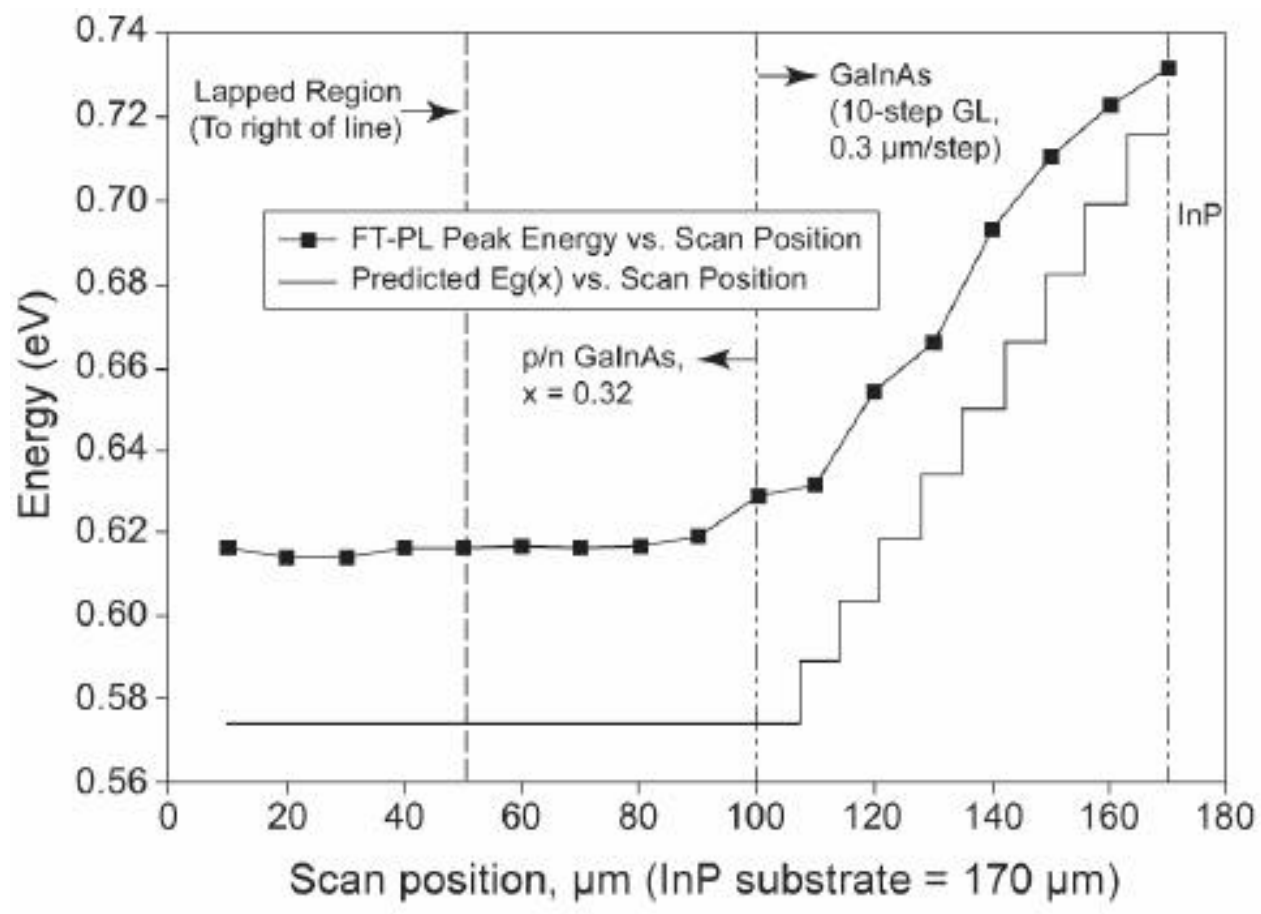

FIGURE 7. FT-PL peak energies vs. line map position on angle-lapped TPV device \#1-213, compared to the predicted bandgap of the device.

$\mathrm{E}_{\mathrm{g}}(\mathrm{x})$ is expected to arise from thermal band filling, which is significant at room temperature, and could be more pronounced in doped material (1). Allowing for these effects, the PL band maxima track the composition of the material closely. There is some "anticipation" of the increase in $\mathrm{E}_{\mathrm{g}}(\mathrm{x})$ in the GL at $100 \mu \mathrm{m}$ in the line scan, indicating that the excitation penetration depth may correspond to about a single scan interval, or that the effective excitation depth is approximately $\left[10 \mu \mathrm{m} * \sin \left(2.5^{\circ}\right)\right]$, or about $0.4 \mu \mathrm{m}$. A similar variation in PL peak energies with scan position was obtained from a micro-FT-PL line map of angle-lapped TPV device 1-216, which incorporated a continuously graded layer (CGL) of $\mathrm{Ga}_{\mathrm{x}} \mathrm{In}_{1-\mathrm{x}} \mathrm{As}$. However, the PL peak intensities measured during the linear scan of Device 1-216 (not shown) were much more variable than those measured for Device 1-213 (Figure 5), perhaps in part because the angle-lapped portion of Device 1-216 was visibly rougher than the lapped portion of Device 1-213.

In Fig. 8, the PL intensities obtained from two successive micro-FT-PL line scans of angle-lapped TPV device 1-217 are shown, together with the device structure. Two scans in identical locations with different detectors were required because the $\mathrm{Ga}_{\mathrm{x}} \mathrm{In}_{1}$ ${ }_{x} \mathrm{As}$ and $\mathrm{InAs}_{\mathrm{y}} \mathrm{P}_{1-\mathrm{y}}$ layers emit PL within the response ranges of the $\mathrm{InSb}$ and $\mathrm{Ge}$ detectors, respectively, and the detectors cannot collect data simultaneously. 


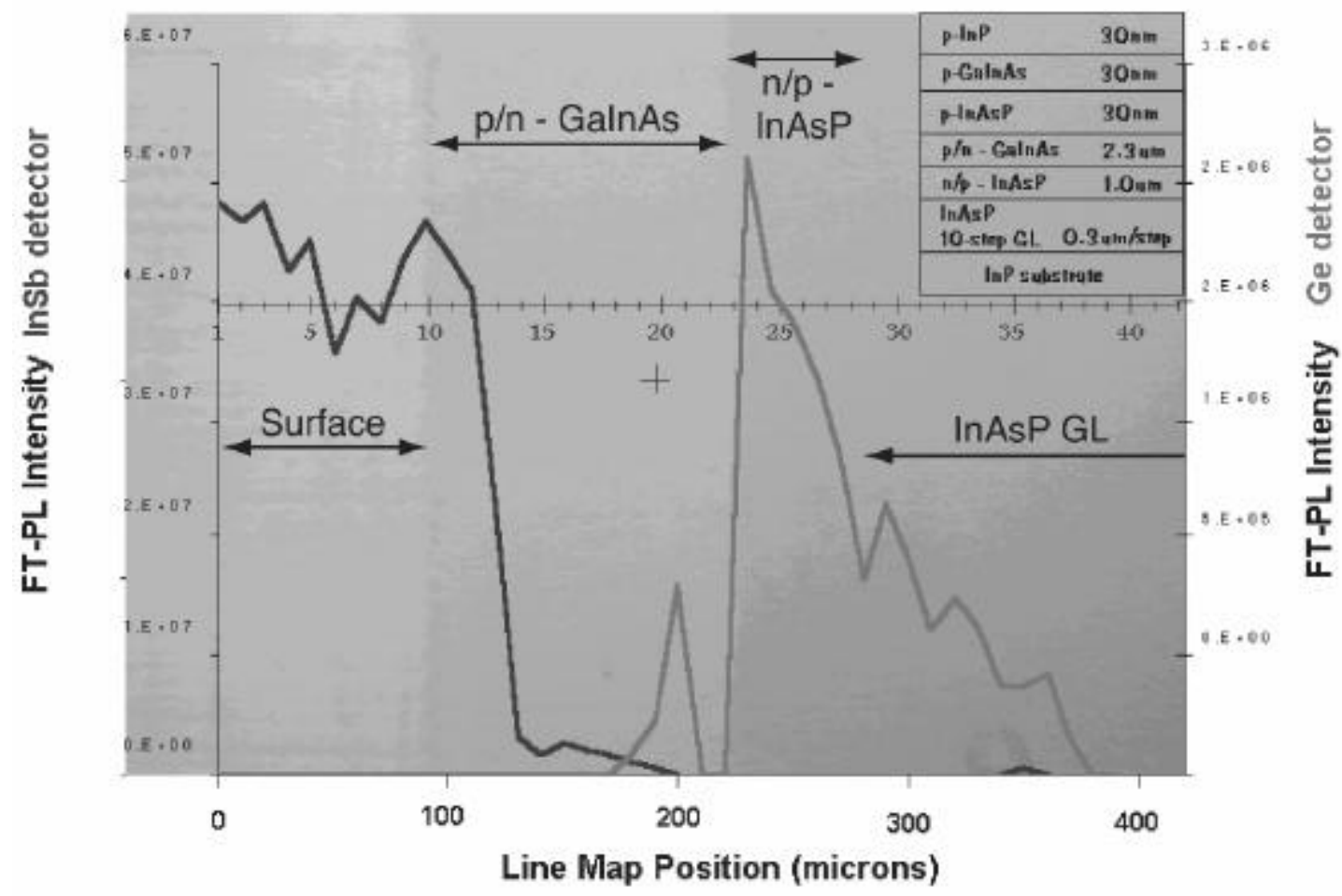

FIGURE 8. FT-PL peak intensity (InSb and Ge detectors) vs. line map position for TPV device \#1217, superimposed on a micrograph of the device. The number line shows where the FT-PL spectra were collected on the angle-lapped device.

The maximum PL intensities apparently differ by about an order of magnitude between the two sets of data in Fig. 8, but the detectors are uncalibrated, although an instrument spectral response correction has been applied to the FT-PL data. An interesting feature in Fig. 8 is the overlap in PL emission characteristic of $\mathrm{Ga}_{0.32} \mathrm{In}_{0.68} \mathrm{As}$ and $\operatorname{InAs} \mathrm{s}_{0.32} \mathrm{P}_{0.68}$ in the line scan region between 175 and $200 \mu \mathrm{m}$, which corresponds to the lower portion of the $\mathrm{p} / \mathrm{n} \mathrm{Ga}_{0.32} \mathrm{In}_{0.68} \mathrm{As}$ layer. This is apparently related to penetration of the lower few tenths of a micron of this layer by the excitation radiation, as described previously. The non-luminescent area at the $\mathrm{n} / \mathrm{p} \operatorname{InAs} \mathrm{s}_{0.32} \mathrm{P}_{0.68} /$ InAs $\mathrm{P}_{1-\mathrm{y}}$ step-GL interface is also of interest. The abrupt drop in PL intensity midway through the line scan of the $\mathrm{p} / \mathrm{n} \mathrm{Ga}_{0.32} \mathrm{In}_{0.68}$ As layer is especially evident in Fig. 9, which is a superposition of the line scan micro-FT-PL spectra collected using the InSb and Ge detectors. The apparently high rate of non-radiative recombination in this region may coincide with defects in the n-layer, although replicate scans of this device would be needed to verify this hypothesis. 


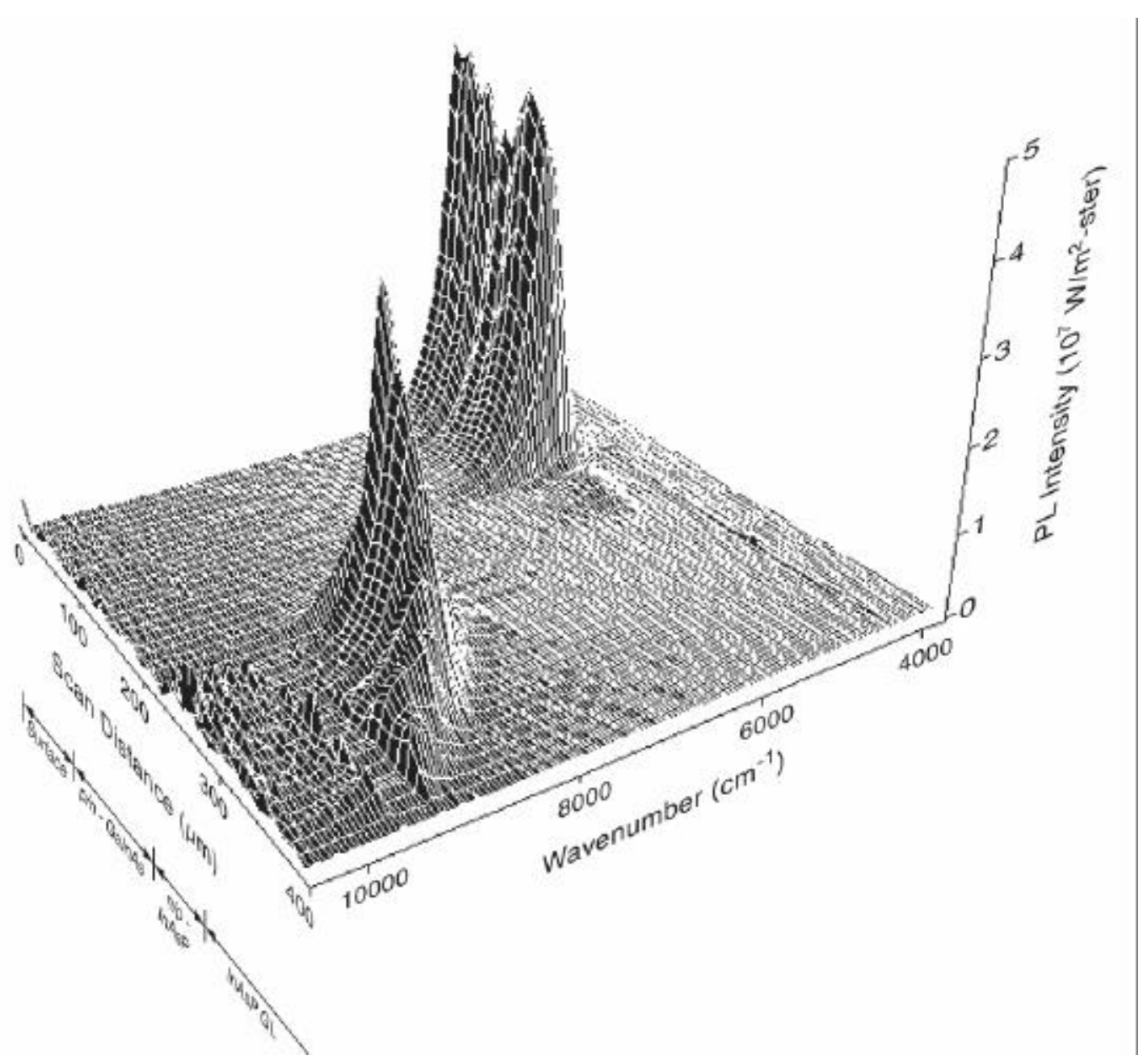

FIGURE 9. FT-PL spectra vs. line map position on angle-lapped TPV device \#1-217.

\section{CONCLUSIONS}

Fourier transform spectroscopic techniques for photoluminescence and infrared reflectance offer powerful tools for TPV device characterization. We are integrating these techniques into a regular protocol with inputs to TPV device characterization, modeling, quality control, and troubleshooting. Algorithms for extracting bandgap estimates from the FT-PL spectra of $\mathrm{Ga}_{\mathrm{x}} \mathrm{In}_{1-\mathrm{x}} \mathrm{As}$ and $\operatorname{InAs}_{\mathrm{y}} \mathrm{P}_{1-\mathrm{y}}$ are also being developed. 


\section{ACKNOWLEDGMENT}

We acknowledge the contribution of the late Paul McKenna of Surface Optics Corporation, San Diego, CA 92131 in measuring the reflectance of the cadmium stannate samples using the SOC-100 absolute reflectometer.

\section{REFERENCES}

1. Wanlass, M. W., Solar Energy Materials and Solar Cells, 41/42 (1996), p. 405.

2. Griffiths, P.R., and De Haseth, J.A., Fourier Transform Infrared Spectroscopy, John Wiley \& Sons, New York, 1986.

3. Wu, X., Mulligan, W. P., Webb, J. D., and Coutts, T. J., "TPV Plasma Filters Based on Cadmium Stannate," presented at the $2^{\text {nd }}$ NREL Conference on TPV Generation of Electricity, AIP Conf. Proc. 358, 1995, pp. 329-338.

4. Charache, G. W., DePoy, D. M., Baldasaro, P. F., and Campbell, B. C., "Thermophotovoltaic Devices Utilizing a Back Surface Reflector for Spectral Control," presented at the $2^{\text {nd }}$ NREL Conference on TPV Generation of Electricity, AIP Conf. Proc. 358, 1995, pp. 339-345.

5. Gu,S.Q., Chen, D. Viner, J.M., Raikh, M.E., and Taylor, P.C., in Noufi, R., (Ed.), AIP Conference Proc., Vol. 268, American Institute of Physics, New York, 1992, p. 363.

6. A. Yamada, M. Tanda, S. Manaka, H. Sano, M. Konegai, and K. Takahashi, in L. Guimaraes (Ed.), Proc. $11^{\text {th }}$ European Photovoltaic Solar Energy Conference, Harwood, Switzerland, 1992, p. 128.

7. J. D. Webb, D. J. Dunlavy, T. Ciszek, R. K. Ahrenkiel, M. W. Wanlass, R. Noufi, and S. M. Vernon, Appl. Spectrosc., 47, no. 11 (1993), 1814.

8. J. D. Webb, D. J. Dunlavy, T. Ciszek, R. K. Ahrenkiel, M. W. Wanlass, R. Noufi, and S. M. Vernon, in O. J. Glembocki (Ed.), Proc. Mat. Res. Soc. Symp., Vol. 324, Materials Research Society, Pittsburgh, 1994, p. 233.

9. J. D. Webb, M. Contreras, and R. Noufi, in D. J. Flood (Chair), Proc. $24^{\text {st }}$ IEEE Photovoltaic Specialists Conference, Institute of Electrical and Electronic Engineers, New York (1994), p. 275.

10. J. D. Webb, B. M. Keyes, K. Ramanathan, P. Dippo, D. W. Niles, and R. Noufi, in C. E. Witt (Ed.), Proc. AIP, Vol. 314, American Institute of Physics, Woodbury, New York, 1996, p. 573.

11. B. Schrader, in D. B. Chase and J. F. Rabolt (Eds.), Practical Fourier Transform Infrared Spectroscopy, Academic Press, New York, 1990, Chap. 4.

12. T. L. Wangensteen, M. W. Wanlass, J. J. Carapella, H. R. Moutinho, A.R. Mason, J. D. Webb, and F. A. Abulfotuh, in Proc. $26^{\text {th }}$ IEEE Photovoltaic Specialists Conference, Institute of Electrical and Electronic Engineers, New York (1997), p.967.

13. Webb, J. D., Keyes, B. M., Ahrenkiel, R. K., Wanlass, M. W., Ramanathan, K., and Jones, K. M., "Fourier Transform Luminescence Spectroscopy of Semiconductor Thin Films and Devices," Vibrational Spectroscopy, in press (1998).

14. Broman, L., Jarefors, K., Marks, J., and Wanlass, M., "Efficiency Measurements of TPV Cells," presented at the $3^{\text {rd }}$ NREL Conference on TPV Generation of Electricity, AIP Conf. Proc. 401, 1995, pp. 463-469.

15. Ballinger, C., et al., "Computational Results for a MIMS Device with Back Surface Reflector (BSR)," to be presented at the $4^{\text {th }}$ NREL Conference on TPV Generation of Electricity, AIP Conf. Proc. $\boldsymbol{X} \boldsymbol{X} \boldsymbol{X}, 1998$, in press.

16. P. Bhattacharya (Ed.), Properties of Lattice-Matched and Strained Indium Gallium Arsenide, Short Run Press, Ltd., Exeter, UK, 1993, p. 7. 